\title{
Ciudad, vacío y emoción. Teatralidad e imagen dialéctica en El cartógrafo de Juan Mayorga
}

\section{City, emptiness and emotion. Theatricality and Dialectical Image in El cartógrafo by Juan Mayorga}

\author{
ANA GORRÍA FERRÍN \\ Consejo Superior de Investigaciones Científicas \\ ana.gorria@cchs.csic.es
}

Recibido: 30-01-2012

Aceptado: 28-10-2012

\section{Resumen}

En este artículo se analizará la obra de teatro El Cartógrafo de Juan Mayorga y el concepto de ciudad que se sostiene. Este trabajo tiene como objetivo desarrollar el concepto de la ciudad y de la imagen dialéctica desde el punto de vista de la conceptualización de la filosofía de la historia que deriva de esta obra y analizar la relación entre el hombre y la ciudad que se propone en esta pieza dramática. Al mismo tiempo, se lleva a cabo una propuesta de descripción analítica de los mecanismos y recursos poéticos, retóricos y estéticos que el autor desarrolla para llevar a cabo su propuesta teatral y la tematización poética y ética de este trabajo.

Palabras claves: Teatro, Juan Mayorga, Análisis del discurso, Retórica, Holocausto, Filosofía de la historia, Imagen dialéctica, Punctum.

\begin{abstract}
This article will analyze the play El cartógrafo by Juan Mayorga and the concept of city included in it. This article aims to develop the notion of the city and dialectal image from the point of view of the conceptualization of philosophy of history that derives from this work at the same time to analyze the relationship between man and city is proposed in this work. At the same time, carry out a proposed ana-
\end{abstract}


lytical description of the mechanisms and poetics, aesthetics and rethorics resources that the author develops dramatic to carry out its proposal stage and the poetic and ethical thematization of this work.

Keywords: Theatre, Juan Mayorga, Discourse Analysis, Rhetoric, Holocaust, Philosophy of history, Dialectical image, Punctum.

\section{Introducción}

La obra El cartógrafo-Varsovia, 1: 400.00 de Juan Mayorga, una de las más recientes obras del autor español, es una pieza a día de hoy inédita pero que ha sido puesta en escena a través de diversas lecturas dramatizadas y traducidas al inglés y francés. Esta pieza ocupa un lugar privilegiado en el corpus de la dramaturgia de su autor ya que atravesada por las principales preocupaciones que caracterizan su obra: la puesta en escena de la Shoah, la reflexión y la necesidad de hacer un teatro histórico, la memoria como elemento articulador de la vida pública y las relaciones entre arte y sociedad ${ }^{1}$.

Es posible llamar la atención como estímulo seminal para esta pieza dramática de mayor envergadura escénica y ambición, además, la obra 581 mapas publicada en la antología Teatro breve para minutos ${ }^{2}$ donde la figura del cartógrafo ocupa un lugar esencial.

La pieza dramática presenta la búsqueda de la verdad partiendo del documento fotográfico y la relación entre dos tiempos: el pasado (ceñido al momento de la creación del Gueto de Varsovia, establecido por el General Hanks Frank el dieciséis de octubre de 1940, a su levantamiento el 16 de mayo de 1943 y a distintos momentos del régimen comunista) y la actualidad. Una relación que se articula a través de la indagación en una leyenda popular de Blanca, asentada en Varsovia debido al trabajo como observador externo de su marido Raúl.

Las treinta y nueve escenas que componen esta pieza dramática articulan esa dialéctica entre pasado y presente hilada por la búsqueda tenaz de Blanca. De esta manera, es posible considerar esta obra una pieza de teatro histórico ${ }^{3}$ ya que, según

\footnotetext{
${ }^{1}$ García Barrientos, J-L, «El Holocausto en el teatro de J Mayorga», en Un espejo que despliega. El teatro de J Mayorga, Facultad de Filosofía y Humanidades, Universidad Nacional de Córdoba. 2011. 2 Mayorga, J, Teatro para minutos, Madrid, Ñaque editora, 2005.

3 Francisca Vilches Frutos ha destacado la pervivencia y la centralidad del teatro histórico como clave en la producción escénica contemporánea distinguiendo cuatro etapas a partir de 1975. En un primer lugar destaca un primer periodo que comprende desde 1975 a 1981 donde se produce la recuperación de textos que fueron silenciados por la censura. En segundo lugar propone un espacio de proyección escénica en que tanto la guerra civil como la Democracia se presentan como personajes históricos, etapa que abarca desde 1982 a 1987. Al periodo de producción escénica que se corresponde con el
} 
Juan Mayorga, el drama histórico se basa en "aquello que anuda dos tiempos y permite sentir como coetáneo nuestro al hombre de otra época"4, debido a que el tiempo y espacio escénico se extiende, tal y como subraya la primera acotación textual: "En Varsovia, entre 1940 y la actualidad"5.

La fábula dramática, en consecuencia, lleva a cabo la imbricatura de esos dos segmentos históricos a través de la yuxtaposición de escenas y se inicia con un comienzo in medias res. Este comienzo presenta el extravío de Blanca en la ciudad de Varsovia y su llegada incidental a una sinagoga donde se prepara una exposición fotográfica que tiene como motivo el Gueto de Varsovia.

Una exposición donde se revela el pasado a través de las escenas que se intercalan con el presente de Blanca y Raúl en Varsovia y cuya presencia anima la imaginación creadora de Blanca para profundizar en la memoria en relación con las tradiciones orales que los propios descendientes de los habitantes del Gueto le transmiten.

Así, esta obra se vincula a otras obras teatrales del autor como Himmelweg 6 o El Jardín quemado 7 en el tratamiento que concede la poética dramática a la historia. De este modo, las relaciones entre la condición poética y la condición política de la experiencia estética hallan un punto de encuentro y diálogo en el tratamiento de la historia capaz de superar el conocimiento de esta última como ciencia analítica a través de la imaginación sensible, porque esta abriga la posibilidad de la memoria íntima.

No obstante, y pese a que es posible trazar líneas concomitantes (que confirman la unidad de la poética mayorguiana en relación con la totalidad de su dramaturgia) es preciso destacar la originalidad de esta respecto a otras obras en las que también se presenta el tratamiento de la ciudad (véase, por ejemplo, la escena de la plaza del reloj en Himmelweg o el universo de la opinión pública representado en Hamelin8 por el periodismo). Es en este caso, el espacio urbano como experiencia histórica $-\mathrm{y}$ forma de gnosis- se convierte en el protagonista que encierra la verdad.

\footnotetext{
lapso temporal que abarca desde 1998 a 1995 lo denomina período del desencanto para concluir con un último período que en la categorización de la investigadora propone un período en el que la dramaturgia histórica procede a llevar acabo un ejercicio de desmitificación del presente/ pasado. Vilches Frutos, F, «Teatro histórico: la elección del género como clave de la escena contemporánea» en Teatro histórico (1975-1998), textos y representaciones: actas del VIII Seminario Internacional del Instituto de Semiótica Literaria, Teatral y Nuevas Tecnologías de la UNED, Cuenca, UIMP, 25-28 de junio, 1998, Madrid, Visor Libros, 1999.

${ }^{4}$ Mayorga, J, «El dramaturgo como historiador», Primer Acto, 280 (1999), pp. 8-10.

5 Mayorga, J, El cartógrafo, documento de trabajo, p. 2. El título es provisional también.

6 Mayorga, J, Himmelweg; Introducción de José-Luis García Barrientos, Málaga, CEDMA, 2005.

7 Mayorga, J, El jardín quemado; Introducción de Virtudes Serrano, $2^{\circ}$ ed. Murcia, Ediciones de la Universidad de Murcia, 2007.

8 Mayorga, J, Hamelin, Madrid, Ñaque editora. 2005.
} 


\section{Lugar, vacío y emoción}

La estructura in media res con la que se inicia El cartógrafo se apoya de manera fundamental en la acción que supone la obertura de la escena:

Raúl- ¿Cómo estás? ¿Estás bien?

Blanca- Estoy bien.

Raúl- ¿Qué ha pasado?, ¿dónde estabas? Ya no sabía qué hacer. He llamado a la policía, a los bomberos, creo que he llamado a todos los hospitales de Varsovia. ${ }^{9}$

Este acto de desubicación que admite una lectura en que espacio y existencia actúan de manera metafórica y solapada, supone tanto el arranque de la obra como la caracterización in medias res de dos de sus protagonistas: Raúl y Blanca.

La acción dramática en esta obra supone una puesta en escena de la ciudad que cabe leerse también como relativa a la dialéctica entre documento y monumento, dada la importancia que se le confiere a la modelización fotográfica 10 en la acción dramática.

Esta dialéctica equilibra las acciones y el diálogo, de manera que es posible ver actuar el pasado ${ }^{11}$ en interacción con el presente a través de las referencias a acciones desarrolladas por los personajes en el pasado y que se corresponden, como un estarcido, a la búsqueda y disposición de la verdad.

\footnotetext{
9 Mayorga, J, El cartógrafo de Hurbineka. Varsovia, 1:400.000, inédita, no estrenada (copia de trabajo), p.3.

10 En El cartógrafo la fotografía no solo aparece tematizada en la acción dramática (la visita a una exposición de fotografía es la que promueve la acción principal) sino también forma parte de la arquitectura retórica de la obra (en algunas escenas de tiempo suspendido, en que se intercalan, de manera dialéctica, distintos estadios temporales) legibles desde la teorización barthesiana alrededor de la ontología fotográfica en relación a la memoria y a la conceptualización de la temporalidad. Gorría Ferrín, A, «Teatralidad y representación de la historia. Ética, memoria y acción suspendida en la dramaturgia de Juan Mayorga» en El Futuro del Pasado, nº 3, 2012, pág. 485.

11 En relación al tratamiento del pasado en la poética dramática de J Mayorga, Davide Carnevali ha destacado: "Mayorga si propone un'operazione del tutto simile condotta per mezzo dello strumento drammaturgico; si tratta in sostanza di destabilizzare la visione preconcetta con cui lo spettatore osserva la storia, tra le cui cause si può situare la presa di posizione dal punto di vista di un'ideologia. La produzione mayorguiana si approccia con intento de-costruttivo tanto alla mitologia franchista (El jardin quemado) quanto a quella repubblicana (Siete hombres buenos); si occupa del rapporto tra l'intellettuale e la cultura di partito tanto in ambito comunista (Cartas de amor a Stalin, 1998), quanto in quello nazionalsocialista (El traductor de Blumemberg). L'intento del 'teatro histórico' mayorguiano è quello di rompere con quelle convinzioni radicate dalla e nella tradizione, che fanno in modo che lo spettatore si illuda di possedere i mezzi per conoscere e descrivere il passato". Carnevali, D, Per un teatro critico: Strategie e tendenze drammaturgiche nell' opera di J Mayorga, Tesis doctoral inédita, Università degli studi di Milano, p. 191.
} 
Así las referencias a las fotografías en las distintas escenas: "Un anciano congelado como en una fotografía"12; en la escena cuatro la acotación afirma "Congelados como en fotografías, el Anciano y una Niña"13; en la escena seis se introduce la siguiente aserción: "La niña mide distancias con sus pasos. Blanca camina siguiendo un mapa ${ }^{14 " ;}$ en la escena quince, se amplía el círculo de personajes: "La niña mide distancias con sus pasos. Blanca dibuja en la tierra un mapa. Deborah camina ${ }^{15 " ;}$ en la escena veintiuno, la acción en la acotación se amplía: "Raúl observa la silueta vacía de Blanca. Suena el silbato. El anciano y la niña se tienden en el suelo, boca arriba, inmóviles 16"; en la escena veinticinco se propone en la acotación escénica: "El Anciano, solo. Suena el silbato. Se tiende en el suelo, boca arriba, inmóvil".

En la escena veintinueve: "El anciano y la niña, tendidos en el suelo, boca arriba, inmóviles. Blanca ante su silueta vacía. Por fin, dibuja sobre ella"17 para culminar en el último fragmento de tiempo suspendido, en la escena treinta y nueve, donde el protagonismo de la niña impele a la acción del nosotros: "La Niña entra. Elige una baldosa del suelo, la levanta; en el reverso de la baldosa hay marcas. La Niña saca un punzón y hace otra marca. Si diésemos la vuelta a todas las baldosas, las veríamos como cuadrículas de un mapa de Varsovia"18.

El alto índice de escenas que remite a acciones escénicas que prescinden de lo verbal, sugiere el carácter, por un lado, altamente teatral de la obra y, por el otro, el carácter literario con el que ésta se proyecta, capaz de sobrevivir o de manifestarse de forma independiente a su proyección escénica.

No obstante, la disposición dramática del tiempo escénico en estas escenas alógicas tiene consecuencias importantes tanto en la disposición de la fábula como en la proyección de la visión dramática que presenta. Las acciones se apoyan en una poética específica y estrictamente corporal que se centra en la significación de los cuerpos suspendidos y que merece un análisis más amplio en función del punctum 19 que se pone en escena

De esta manera, cabe subrayar que la función poética es una de las características primordiales que constituye esta obra de manera paralela a la función dramática y a la función ideológica porque resulta evidente que la disposición de la arquitectura dramática depende la tematización de la visión. Al mismo tiempo es destacable la ausencia total de acotaciones como deixis escénica.

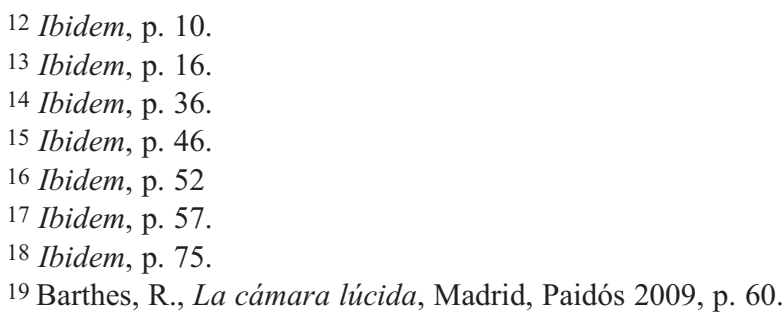


Un aspecto que es legible -la ausencia de referencias espacio temporales como marco de referencia de la teatralidad- a través del aspecto tematizado en la fábula dramática de búsqueda de la verdad a través de una dialéctica tiempo-espacio. Así se privilegia tan solo la deixis personal que señala las transacciones comunicativas en las escenas y se caracteriza a los personajes a través del nombre. Un hecho que incluso en las escenas de tiempo suspendido solo es sustituido por una referencia nominal que delimita el ámbito del personaje.

Si bien las funciones que más peso específico tienen en el texto son la función dramática y la función poética, presente en la poética corporal de las escenas del tiempo suspendido, es importante destacar que por el juego de tiempos que se establece en escena la función diegética tiene una importante repercusión en la exposición y tematización de la fábula.

Esto es debido a su organización alrededor de las narraciones y relatos (que los agentes de la acción no conocen entre sí) para hilvanarse en el presente de la acción dramática. La función metadramática se encuentra ausente y la función caracterizadora apenas se encuentra presente más allá de los esbozos sugeridos en la deixis personal y presentes en la disposición dialógica.

\section{La escala de los mapas}

En relación con esta visión de la historia referida al dramaturgo como historiador, es preciso destacar la diversidad de registros que acontecen en la escena. Son muchos los núcleos que se articulan en la fábula dramática: el familiar-afectivo, el procesal con distintos grados de relación que afectan al ámbito íntimo-amoroso y al ámbito procesal; los interrogatorios desarrollados durante la Polonia comunista.

Este motivo delimita, también, los registros lingüísticos desarrollados en el drama y que admiten también la variación social en el habla del anciano, de la niña y del diálogo entre extranjeros. Relaciones que suponen, además, temas tangenciales de la obra, en los que el registro íntimo aparece también dividido en función de las interlocuciones que se establecen.

La forma en la que se manifiesta el diálogo es a partir de núcleos de interacción en cada uno de los niveles temporales que alcanzan su aglutinación en las escenas de tiempo suspendido. La acción o acciones que constituyen esta obra dramática, articulada por los dos niveles temporales distintos, que se resuelve en la temporalidad dramática, son susceptibles de ser entendidas como una búsqueda pericial que atañe a la memoria a través de la exploración del documento (exposición de fotografía sobre el Gueto de Varsovia).

Así, tras la situación inicial en que Blanca y Raúl irrumpen en escena, las acciones giran alrededor de la necesidad de establecer la memoria a través del documen- 
to al que Blanca ha accedido mientras se delimitan las tensiones surgidas en el marco del matrimonio por la vehemencia de la querencia de Blanca y la relación del matrimonio con los oriundos de Varsovia. De manera paralela, se pone en escena el diálogo entre dos víctimas del Gueto de Varsovia y su lucha por la supervivencia a través del testimonio.

La situación inicial, que se convierte en la acción principal de la obra y que no es otra que el deseo de acceso a la verdad de Blanca, promueve una fábula dramática de gran dificultad debido a los juegos temporales que se establecen y que es posible postular como pasado dramático, presente dramático y tiempo literario, aspecto que procederé a detallar con posterioridad.

No es posible en consecuencia establecer una distinción entre acciones primarias y secundarias. La pieza se compone de dramas superpuestos que coinciden en la teatralidad entendida como un cronotopo específico. En todo caso, es posible proponer una organización no jerárquica de acciones primarias en las que tanto el deseo de Blanca como la fábula dramática (es decir, en última instancia, la búsqueda de la verdad en el espacio de la ciudad más allá de la dialéctica entre monumento y documento) se encuentran equiparadas:

Blanca- El Gueto. Un hombre estaba poniendo los cartelitos. Bajo cada foto, en polaco y en inglés, la calle donde se cree que se hizo la foto. Se ve cómo organizaban el transporte, porque los coches estaban prohibidos pero tenían un tranvía, y taxis de pedales. El comercio, la policía. Tenían su propia policía. ${ }^{20}$

De esta manera, la obra de Juan Mayorga mantiene una dimensión temporal y estructural atomizada en la que solo se mantiene la unidad espacial. Este hecho es debido a la importancia que se le concede a la ciudad en la arquitectura de sentido que propone la obra y que más allá del espacio retórico y poético de la articulación de la ciudad tiene, en último sentido, una consecuencia ética.

Anciano- ¿Has salido? ¡Has salido del Gueto!

Niña- En cada vagón meten cien. Sesenta vagones.

Anciano- No deberías haber vuelto. Deberías haberte quedado allí. Tienes que volver allí.

Niña- Seis mil al día.

Anciano- ¿Qué hace el Consejo? ¿Qué hace Czerniakow?

Niña- Los alemanes le pusieron delante un documento para que lo firmase. Una solicitud para que los alemanes se lleven a aquellos a los que el Consejo no pueda alimentar. Czerniakow pidió que lo dejasen solo, para pensar. Tenía cianuro. Mucha gente tiene cianuro.

20 Mayorga, J, op.cit (nota 9), p. 3. 
Anciano- ... Sabes cómo salir. Puedes sacar gente. Utiliza lo que sabes para salvar vidas. Una vida es más importante que todos los mapas del mundo.

Niña- Seis mil al día.21

En consecuencia las acciones, en la constelación de fuerzas referida, aunque contienen subtramas o tramas secundarias en cada una de los niveles, no aceptan ser leídas desde una manera hipotáctica sino paratáctica en la configuración de la trama. En relación a las acciones, en las que se constituye la totalidad de la obra, es preciso subrayar que esta no se estructura de manera clásica y no cumple el esquema causal de planteamiento, nudo y desenlace.

La causalidad de la trama, sin una única acción principal, es susceptible de ser leída desde una estructuración rizomática en la que los distintos elementos concatenados de una forma no jerárquica se condicionan de forma recíproca en una fábula dramática abierta cuyo clímax no es susceptible de ser leído como desenlace.

Así el final funciona como apertura (la acción culmina con la exhibición diégetica del mapa invisible, motivo fundamental de la trama y con un apunte condicional "si diésemos la vuelta a todas las baldosas, las veríamos..."22). En este desenlace, en consecuencia, se resuelve en la imagen dramática y no en la acción dramática porque se plantea a través de la referencia deíctica al nosotros una experiencia comunitaria en que la última acción es el conocimiento, ya no solo por parte de los personajes, sino también de la comunidad que participa en la obra dramática.

En las tres acciones principales se pone en escena la interacción temporal como una imagen dialéctica que es susceptible de ser leída como una puesta en escena del materialismo histórico desarrollado en la filosofía de la historia de Walter Benjamin, autor en cuyo pensamiento Juan Mayorga es especialista23.

La riqueza de niveles de El cartógrafo nos lleva a considerarla tanto un "drama de personajes" como un "drama de ambiente" debido a la importancia y centralidad del hecho histórico del Gueto de Varsovia y la atención prestada al totalitarismo soviético. Ambas formas de tematización de la obra se encuentran ligadas a través de la imagen dialéctica como módulo estructurador.

\section{La imaginación dialéctica}

He referido ya que uno de los hallazgos que supone este texto frente a otras obras de la dramaturgia actual que abordan la perspectiva histórica, es el uso de la

\footnotetext{
21 Mayorga, J, op.cit (nota 9), p.3. Ibidem, p.41.

22 Mayorga, J, op.cit (nota 9), p.41.

${ }^{23}$ Mayorga, J., Revolución conservadora y conservación revolucionaria: política y memoria en Walter Benjamin. Barcelona, Anthropos, 2003.
} 
imagen dialéctica que se presenta en la pieza y que denota un uso particular de la estética con productividad ética en esta obra.

Este aspecto vincula el teatro histórico de Juan Mayorga y, en concreto, la obra propuesta para su análisis a la producción dramática de Buero Vallejo tanto en su análisis de los procesos históricos como en la arquitectura de sentido dispuesta en sus obras. A la hora de revisar el drama histórico como un espacio de proyección escénica en el que se desarrolla de manera dialéctica la relación entre el pasado y el presente Ruiz Ramón examina los procesos retóricos y poéticos presentes en la obra de Buero Vallejo y de Domingo Miras .

El estudioso distingue como constantes de las dos dramaturgias su capacidad tanto didáctica como catártica. El historiador de teatro español a partir del examen de la producción de estos dos autores sostiene que:

El llamado tiempo histórico no es tal, sino puro tiempo de la mediación. O, a lo menos, un tiempo que no existe sino como mediación dialéctica entre el tiempo del pasado y el tiempo del presente, un tiempo construido en el que se imaginan, se inventan o se descubren nuevas relaciones significativas entre pasado y presente capaces de alterar el sentido tanto del uno como del otro, así como del uno por el otro. ${ }^{24}$

Las categorías espacio temporales contribuyen a la significación ética. Tiempo y espacio son los elementos esenciales de la imagen dialéctica que se nos presenta en esta fábula dramática. En ese uso que resulta productivo tanto en lo ético como en lo estético para la escenificación y dinamización de los conflictos que se ponen en escena a través de la búsqueda en conflicto de los personajes con su propia actualidad y con la historia en ambos planos temporales. Un agón en el que se interpolan, como ya he procedido a señalar, distintos niveles de temporalidad en el espacio concentrado de la ciudad de Varsovia y, con más exactitud, en el espacio del Gueto de Varsovia.

En la dramaturgia de El cartógrafo es la dimensión urbana la que orienta la dirección significativa en que se constituye la obra de manera que es posible afirmar que es el espacio el que se articula de manera dialéctica. Este hecho se produce a través de la exposición abierta que supone la confrontación del ahora y la percepción de lo perdido, encarnado en la búsqueda de Blanca y puesto en escena en las imágenes que suponen el encuentro como presente radical entre la actualidad y lo perdido.

Todo presente está determinado por aquellas imágenes que le son sincrónicas: todo ahora es el ahora de una determinada cognoscibilidad. En él, la verdad está cargada de

24 Francisco Ruiz Ramón, «Apuntes para una dramaturgia del drama histórico español del siglo XX», en VV. AA., Actas IX. AIH, 1986, p. 387. 
tiempo hasta estallar. (Un estallar que no es otra cosa que la muerte de la intención, y por tanto coincide con el nacimiento del auténtico tiempo histórico, el tiempo de la verdad). No es que lo pasado arroje luz sobre el presente, o lo presente sobre lo pasado, sino que imagen es aquello en donde lo que ha sido se une como un relámpago al ahora en una constelación. En otras palabras: imagen es la dialéctica en reposo. Pues mientras que la relación del presente con el pasado es puramente temporal, la de que de lo que ha sido con el ahora es dialéctica: de naturaleza figurativa, no temporal. Sólo las imágenes dialécticas son imágenes auténticamente históricas, esto es, no arcaicas. La imagen leída, o sea, la imagen en el ahora de la cognoscibilidad, lleva en el más alto grado la marca del momento crítico y peligroso que subyace a toda lectura. 25

El tratamiento de la temporalidad y la espacialidad es muy complejo y supone uno de los elementos más importantes de la obra. En esta obra, la tematización del espacio se lleva a cabo a través de la caracterización física, metafísica e incluso ética a través de la acción de los personajes principales.

En consecuencia, la caracterización del espacio es referido a través tanto de la acción como de la interacción de los personajes de manera diegética y metadiegética:

Niña- ... Alex Krunz, que trabajaba en el barrio ario, por traer escondido un paquete de mantequilla. Andrei Boz por imprimir documentación falsa. Los hermanos Butchovski, encargados del transporte del taller de zapatos, se les murió un caballo y los acusaron de sabotaje. Bavel Fink, por no entender una orden. Karen Brycik, por caminar por la calle Ogrodowa. En Ogrodowa está prohibido pasear, pero nadie recuerda haber leído esa prohibición. Bert Wabeck, dicen que lo hizo nuestra gente, que era un soplón. Un coche negro apareció en la avenida de Szuch y dejó un cuerpo en el 24 de Orla: era Toplitz, el director de la Galería Major, dicen que lo habían cogido en el barrio ario. El coche negro ha vuelto tres veces, siempre viene por la avenida Szuch, siempre los deja en los pares de Orla. Edgar Knoch, en Karmelicka. Alguien hizo un gesto y la calle se quedó desierta, pero Knoch comprendió tarde o fue demasiado lento, el coche negro se paró ante él, le hicieron subir, el coche se alejó por Dzielma, nadie sabe por qué se llevaron a Edgar Knoch. Andrei Heller. Una mujer decía "Si Heller, el hombre más rico del Gueto, no ha podido salvarse, ¿quién se salvará?’. El maestro Volsky. No llevaba el brazalete. Dicen que se olvidó, aunque su hijo dice que no fue olvido. Pero ya tenemos un nuevo maestro.

Los lugares de la relación entre los distintos personajes también aparecen citados e indicados en el diálogo de los personajes:

Anciano- ... Vamos a empezar la calle Svoda. Vamos a subir por esta acera hasta Tadro. Niña- Mejor por la otra. He oído que aquí han abierto un matadero.

Anciano- ... Está bien, empezaremos por la acera izquierda... Espera. ${ }^{26}$

25 Benjamin, Walter, Libro de los pasajes, Madrid, Akal, 2005, p. 465.

26 Mayorga, J, op.cit (nota 9), p. 30. 
La noción de metadiegésis y de diégesis, debido al carácter de presencia radical en el que se invisten todas las escenas, es elidida y la dilucidación de los procesos es puesta en escena a través de las palabras de los personajes.

Ya que no existen acotaciones, es decir, evidencias indiciales de la temporalidad es preciso acudir a la elaboración temporal de la fábula dramática en el ámbito diegético para poder llevar a cabo una ubicación de la temporalidad. Una temporalidad que se basa en la dialéctica entre tiempos modulada a partir del deambular de la búsqueda de Blanca como acción estructuradora de la ciudad.

Niña- Aquí celebraron el banquete. Aquí le hicieron el traje a la novia. Ésta es la marca de "sastre". Esta columna es la clave de oficios: Carniceros. Ebanistas. Impresores. Peluqueros. Esto son tiendas de empeños. Por estas puertas salen lo que van a trabajar al lado ario. Lugares de reparto de sopa y pan. Centros de refugiados. Aquí han abierto un salón de belleza. Éste es el sitio de Ajkyk el limpiabotas, siempre está preparado con su caja entre las piernas. Aquí, en su mesa de la cafetería Europa, el poeta Szlengel ha escrito esta mañana un poema. El maestro Trachter ha empezado un mural sobre Job. Aquí se reúnen los jóvenes comunistas. Aquí se estrenó ayer "El Dios de la venganza", de Salom Asz. Oficina de impuestos. Las prendas de piel hay que entregarlas aquí. Seis casos de tifus en el orfanato Dimisz. Ésta es la señal de "orfanato"; ésta la de "tifus". Aquí compró el novio su traje por cinco kilos de manteca. Un traje normal son dos kilos de manteca o diez paquetes de cigarrillos Juno o cuatro peines. Esto indica qué se cambia en cada lugar. Es difícil, porque varía con las horas. En el cementerio hay verduras hasta las diez, luego llega la ropa, lo último es el tabaco y las medicinas. Esto indica si sólo se cambia entre gente o también con policías. Leszel Cogehn, lo dispararon cuando cruzaba el muro. En cada casa he puesto dos números. El primero, gente que vive en la casa; el segundo, niños. 27

Es preciso también destacar, a la hora de presentar una reflexión sobre la temporalidad de El cartógrafo, el juego que existe entre fábula y elipsis ya que la temporalidad de la obra (consecuencia de que está planteada como una imagen dialéctica) se pone al servicio de la visión alegórica que esta sostiene o predica en el ámbito más amplio de su tematización.

Una visión, la de la alegoría, en que todos los elementos de la obra (espacio, tiempo, personajes) se postulan como entidades constructoras de una comprensión más amplia, íntima y que no cabe en el espacio de la representación (dado la temporalidad condicional en la que se sitúa la obra).

La importancia del tiempo suspendido en las escenas descritas a lo largo de este artículo y que remite a los modos de codificación de los procesos fotográficos o pictóricos supone también uno de los más importantes anclajes para la tematización del tiempo.

27 Mayorga, J, op.cit (nota 9), p. 30. 27 Ibidem, p. 29. 
Tanto la dramaturgia del espacio y el tiempo de la obra de Mayorga se ponen al servicio de la comprensión dialéctica a través de la acción y de la imagen (en la escenas referidas) como un proceso dialéctico. Una visión que puede ser considerada alegórica, en última instancia, a través de los procesos de comprensión de la historia que sugiere la dialéctica del materialismo histórico.

Una imagen de realidad que concierne al análisis y comprensión de los procesos puestos al servicio de la comprensión del presente respecto a la organización temporal del drama. También la imagen de realidad se pone al servicio de la importancia de la fábula para la función dramática. Este hecho denota el alto grado de teatralidad de la obra y hace preciso señalar la relevancia de las elipsis y las pausas en la construcción del tiempo presente que la obra pone en escena. Fruto de la interacción de niveles temporales surge la interacción con el tiempo dialéctico escenificado en las partes relativas al tiempo suspendido.

En consecuencia es relevante señalar que los nexos que aparecen en las escenas temporales responden al principio de interrupción, llegando a su clímax en las escenas de tiempo suspendido. Unas interrupciones que suponen pausas, elipsis o suspensión temporal absoluta y ucrónica.

La temporalidad que se presenta en la obra está fundada en la acronía. De esta manera lo que se pone en relieve es, a través del simulacro artístico las posibilidades que desarrolla el tiempo como imagen dialéctica a través de la puesta en escena de la ciudad, como un estarcido. La importancia del orden temporal, que no ha de considerarse acrónico en su totalidad, se debe a que la esta es una temporalidad que se convierte en la supraestructura dramática de la obra.

La duración del orden temporal intrínseco no se asimila a la duración de la obra en tanto en cuanto implica un proceso de descubrimiento de la verdad que atañe a la estancia de Blanca en Varsovia como marca temporal más evidente de perspectiva externa. No obstante, también hay un tiempo interno en la estructuración de la fábula que, al entrar en diálogo con la temporalidad externa, crea una nueva temporalidad que supone ser una imagen dialéctica que invita no solo a la comprensión de los procesos históricos sino a la comprensión del drama íntimo y universal que se gesta en el Gueto de Varsovia ${ }^{28}$.

\section{Tiempo e historia}

El núcleo de personajes que aparece en la obra es susceptible de dividirse en función de los distintos núcleos de significación histórica a los que se adscriben:

\footnotetext{
28 Tal y como aclara el autor en su monografía sobre Walter Benjamin: "En Sobre el concepto de historia el tema de la memoria incompleta se refiere a la humanidad en su conjunto. No se trata de recuperar zonas sumergidas del pasado individual, sino de rescatar extensiones condenadas al olvido bajo la tradición hegemónica". Mayorga, J., op.cit (nota 23), p. 73.
} 
tres tiempos históricos distintos que se hilvanan en la fábula dramática como un estarcido. Cada uno de los núcleos históricos se compone del siguiente grupo humano cuyo nexo es el espacio de Varsovia a través del hecho histórico y su constitución como documento: la exposición de fotografía que promueve el deseo de conocer de Blanca.

Los personajes que aparecen en la obra, tal y como he indicado en la sinopsis son, en relación a los núcleos históricos que se presentan (la actualidad del espectador, el régimen soviético polaco en dos momentos distintos y la experiencia del Gueto de Varsovia):

\begin{tabular}{|c|c|c|}
\hline GUETO DE VARSOVIA & $\begin{array}{c}\text { POLONIA COMUNISTA } \\
\text { DOS MOMENTOS }\end{array}$ & ACTUALIDAD \\
\hline ANCIANO & $\begin{array}{c}\text { DEBORAH (1969) } \\
\text { DEBORAH (1980) }\end{array}$ & DEBORAH \\
\hline NIÑA & & BAÚL \\
\hline PUEBLO JUDíO (aludido) & DUBOWSKY (1980) & SAMUEL \\
\hline NAZISMO (aludido) & MOLAK funcionario estatal (1969) & MAREK \\
\hline & ADAM RYVAK (aludido) & MAGDA \\
\hline & & EL EMBAJADOR (aludido) \\
\hline
\end{tabular}

Por tanto, es posible considerar que la estructura del elemento cuantitativo de los personajes tiende a la disgregación (dada la multiplicidad de los ámbitos históricos que se representan) y encuentra unidad en la tematización de la ciudad de Varsovia como escenario del drama histórico que se pone en escena.

Un drama que atañe al tiempo comprendido entre la constitución del Gueto de Varsovia (y la diegésis a través de los diálogos entre anciano y niña de las atrocidades cometidas por la Alemania Nazi), la Polonia comunista (en que se pone en escena el drama de los perseguidos por el totalitarismo soviético) y la actualidad que atañe a un núcleo mayor de personajes más amplio en los que el núcleo central supone la relación de Blanca y Raúl. Los personajes principales coinciden en el tiempo ucrónico y dialéctico de la obra dramática. Los personajes o grupos humanos aludidos son el pueblo judío y los oficiales nazis (referidos a través de la diegésis), Adam Ryvak personaje prófugo en 1980 y El embajador, motivo de la estancia de Raúl y Blanca en Polonia. 


\section{El dolor radicalmente presente}

La obra, pese a presentar cuatro momentos históricos distintos, encuentra un vínculo tanto en el deseo de Blanca de conocer como en el personaje de Deborah que no solo se encuentra presente en la actualidad dramática, sino también en el eco de la leyenda de la niña cartógrafa y en las escenas relativas al período soviético de Polonia. Los personajes patentes son doce y se manifiestan con complejidad de forma pluridimensional e incluso en diversos estadios de su vida.

La naturaleza de los personajes presentada y caracterizada en la propia escena del conflicto se desplaza de forma progresiva hasta llegar a su eclosión final; la propuesta de participación en la memoria a través de la imagen dialéctica que funciona de manera alegórica a través de las escenas del tiempo suspendido en una invitación comunitaria al conocimiento. Las técnicas para construir a los distintos personajes dramáticos son explícitas. Los distintos personajes aparecen caracterizados a través de la interacción verbal y la caracterización se produce en presencia de los personajes a excepción de los personajes aludidos referidos en el cuadro sinóptico presentado.

El cartógrafo se presenta como una obra de personaje dodecafónica con personajes humanizados que tanto desde el punto de vista comunicativo como desde el punto de vista interpretativo mueve a ser leída como ante todo una alegoría de consecuencias éticas no solo sobre la historia sino sobre el horror desarrollado en la ciudad de Varsovia durante la mitad del siglo XX a través de sucesivos totalitarismos.

La distancia temporal que se desarrolla en El cartógrafo en relación con su puesta en escena responde a una visión del presente (como extensión natural de la lógica del materialismo histórico que pone en escena la obra) en que algunos rasgos de una de las acciones primarias implica la identificación del espectador con la puesta en escena de la obra.

El tratamiento de los dos otros núcleos temporales (históricos) y humanos también invita al no distanciamiento, hecho que viene a ser subrayado en las escenas de tiempo suspendido en que coinciden, como imagen dialéctica, los tres núcleos históricos que acontecen en la obra. En consecuencia, El cartógrafo se presenta con decidida vocación de drama contemporáneo, con una distancia comunicativa temporal simple, es decir, de grado cero.

No obstante, a pesar de que la obra busca la implicación del espectador contemporáneo, hecho que se subraya con la primera persona del plural de la función diegética de la última escena-acotación, es preciso destacar que por ser un drama planteado como imagen dialéctica tiene una dimensión universal que expone el sufrimiento humano, la redención y la necesidad de conocer. La referencialidad espacial, Varsovia, se constituye a través de las diferentes referencias que los personajes ofrecen de su núcleo personal al que se encuentran ligados. 
Todos los espacios se encuentran, en consecuencia, tematizados y se ponen al servicio de la función tanto ideológica como dramática del texto. Funciones que se condicionan entre sí; la necesidad y la posibilidad de la comprensión íntima. Los personajes en el ámbito de la interacción mantienen distintas relaciones cuya naturaleza se va modificando a través del conflicto en progreso que supone esta obra dramática como apertura a la comprensión no solo del pasado sino del propio presente a través de la emoción; aspecto encarnado en la búsqueda a través de los sentimientos de uno de los personajes principales, Blanca.

\section{Bibliografía}

BARTHES, R, La cámara lúcida, Madrid, Paidós, 2009.

Benjamin, W, Libro de los pasajes, Madrid, Akal, 2005.

Carnevali, D, Per un teatro critico: Strategie e tendenze drammaturgiche nell' opera di Juan Mayorga, Milán, tesis doctoral inédita. Università degli studi di Milano.

García Barrientos, J-L, Cómo se comenta una obra de teatro, Madrid, Síntesis, 2007.

García Barrientos, J-L, «El Holocausto en el teatro de Juan Mayorga» en Un espejo que despliega. El teatro de Juan Mayorga. Córdoba, Facultad de Filosofía y Humanidades, Universidad Nacional de Córdoba, 2011.

GORRÍA FERRÍN, A: «Teatralidad y representación de la historia. Ética, memoria y acción suspendida en la dramaturgia de Juan Mayorga» en El Futuro del Pasado, no 3. (2012) pp. 481-502.

Mayorga, J, Himmelweg; Introducción de José-Luis García Barrientos, Málaga, CEDMA, 2005.

MAYORGA, J, El jardín quemado, Introducción de Virtudes Serrano. Murcia, Ediciones de la Universidad de Murcia. 2007.

MAYORGA, J, El cartógrafo de Hurbineka. Varsovia, 1:400.000, inédita, no estrenada (copia de trabajo).

Mayorga, J, Hamelin. Madrid, Ñaque editora. 2005.

MAYORGA, J, «El dramaturgo como historiador» en Primer Acto (280) 1999, pp. 810.

MAYORGA, J, Revolución conservadora y conservación revolucionaria: politica y memoria en Walter Benjamin, Barcelona, Anthropos, 2003.

Mayorga, J, Teatro para minutos, Madrid, Ñaque editora. 2005.

Ruiz RAMÓN, F, «Apuntes para una dramaturgia del drama histórico español del siglo XX», en VV. AA., Actas IX, AIH, 1986, pp. 363-388.

VILCHES Frutos, F: «Teatro histórico: la elección del género como clave de la esce- 
na contemporánea» en Romera, J (dir) Teatro histórico (1975-1998) : textos y representaciones : Actas del VIII Seminario Internacional del Instituto de Semiótica Literaria, Teatral y Nuevas Tecnologías de la UNED, Cuenca, UIMP, 25-28 de junio, 1998. Madrid, Visor Libros, 1999. 